\title{
Journology - A New Beginning
}

Nepal Medical Association (NMA) is organizing its $24^{\text {th }}$ All Nepal Medical Conference (ANEMECON) in Kathmadu from April 15-17, 2009. For the first time in the history ANEMECON has started a session for journal known as Journology.

This session will incorporate knowledge sharing regarding journal management, editorial training, editorial ethics, role of editor to the author, peer reviewer, reader, publisher, sponsors and to the community as well. The organizing committee has envisioned that large mass of the community will be sensitized about the need of expert journal editor to run a journal of international standard in the country.

There may be valuable research going on in our country but that may not reach the international community due to published in the poor quality journal. This journal lacks proper management of journal, editorial knowledge, training and recognizing journal editors. Recent changes in the rules and regulations in the institutes has call indirectly for improvement in journal to check the quality of submitted researches which help authors to have academic achievements. If journal editor are not capable enough poor quality articles get published upon which authors get academic achievement and can influence journal and academe as a whole. Thereby a vicious cycle of poor quality of academic environment begins. Because of this reason journal editor has to be competent enough and well trained to take this huge responsibility.

As Marušiæ et al has stated that the editors of small journals have the power and moral obligation to become a stronghold of quality and advancement in their scientific community. Their educational "tools" are editorial integrity and author-friendly policy. Editors can teach the authors study design, statistical analysis, precision, punctuality, research integrity, style and format of writing, and other aspects of scientific communication. ${ }^{1}$

Improvement of medical journal and empowering its editor is not sufficient from local level alone but big scientific journal editor has equally important role to support them.

International associations of editors maybe leaders of these activities by defining, promoting, and perhaps controlling good editorial practice, as a main criterion for international recognition of a journal. However, the editors of small journals have the power and moral obligation to become a stronghold of quality and advancement in their scientific community. Their educational "tools" are editorial integrity and author-friendly policy. Editors can teach the authors study design, statistical analysis, precision, punctuality, research integrity, style and format of writing, and other aspects of scientific communication. The editors of "big", mainstream scientific journals can act as global educators, teaching and providing guidance to editors of small journals. ${ }^{1}$

The time has changed, it is a welcoming step of NMA to incorporate journology to empower and sensitize the large mass of medical professionals who are and could be researchers, author, peer reviewer and future editor to lead the academic medicine in Nepal.

\section{REFERENCE}

1. Marusic M, Marusic A. Good editorial practice: editors as educators. Croat Med J 2001 Apr;42(2):11320. 